Testimonio

\title{
Jorge Gelman: una trayectoria militante en Política Obrera
}

\author{
Sebastián Federico Paris ${ }^{*}$
}

\section{Presentación}

La nota biográfica que se reproduce a continuación fue realizada el 17 de mayo de 2017 y está estrictamente correspondida al itinerario militante que recorrió Jorge Gelman. Dicha entrevista se inscribió en el marco de la exploración histórica de quien escribe, tratando de desentrañar quienes habían formado parte activa de la organización de matriz trotskista Política Obrera (PO), antecesor del actual Partido Obrero ${ }^{1}$. Jorge perteneció y fue protagonista de la "generación setentista", esa innumerable camada de jóvenes que se volcaron apasionadamente a un canal militante (no sin temor a perder su vida) para la superación de la sociedad vigente, en definitiva, a una sociedad más justa e igualitaria. Esa experiencia que transitó los años que van desde 1972, época en la cual ingresa a la organización, hasta poco entrado el año 1984, etapa en que lo encuentra ya distanciado, están cargadas de una intensa conciencia militante. Esta conciencia tomó cuerpo desde sus inicios: cuando Jorge estaba culminando sus estudios secundarios a fines de 1973, decidió dar todo de sí ponderando la proletarización en fábrica ${ }^{2}$ por sobre el ingreso al mundo universitario. La proletarización física de la juventud, que en la actividad ya se realizaba, fue una estrategia compartida por diversos partidos de la izquierda revolucionaria en la Argentina (con más énfasis e interés en el trotskismo) que buscaban abrirse camino para conquistar al -y no quedar aislados de las luchas del- movimiento obrero a quienes ellos consideraban junto con los estudiantes, los sujetos imprescindibles para la transformación y liberación social. Jorge fue un colaborador fundamental en este ambicioso proyecto que lo

\footnotetext{
${ }^{*}$ Universidad de Buenos Aires (UBA) - FFyL, sparis3850@gmail.com

${ }^{1}$ El 24/03/1976 la Junta Militar (compuesta por las tres Fuerzas Armadas), PO fue declarada como una organización "subversiva" y por lo tanto ilegalizada (tal decisión no fue levantada nunca por la justicia). Al retorno de la democracia en 1983 y ante el panorama electoral que se abría, debió cambiarse el nombre a Partido Obrero, el cual conserva hasta el presente.

${ }^{2}$ La resolución adoptada en favor de la proletarización física de la organización. Es decir, la inserción de numerosos militantes en fábrica que tenían el objetivo pasar la prensa y entablar una relación política con los trabajadores para ganarlos a sus ideas (estrategia se verá amortiguada por la hostilización de la burocracia sindical) se dio hacia el año 1966, en el marco de una ofensiva generalizada contra los derechos laborales por parte del gobierno militar de Juan Carlos Onganía.
} 
vio tropezar en mayo de 1975 cuando en el contexto de una aguda militarización y represión del gobierno peronista a la clase obrera, y en particular a la variada militancia de izquierda que se fundía con ella, será apresado por las fuerzas policiales de lo que fue su participación en la huelga general de Villa Constitución.

Luego de haber permanecido y recorrido durante tres años diversas cárceles argentinas (entre ellas, la cárcel de Villa Coronda, radicada, precisamente, en la provincia de Santa $\mathrm{Fe}$ ), el Poder Ejecutivo Nacional accedió a otorgarle el derecho de opción. Es en estas circunstancias que el año 1978 lo tendrá en el exilio francés (con un paso muy breve por Israel), particularmente en París, ciudad en la que ya se hallaba una extensa comunidad de exiliados políticos argentinos. La solidaridad con los emigrados argentinos fue protagonizada básicamente por el PS y la organización trotskista Liga Comunista Revolucionaria (LCR), ya que el PCF se alineaba detrás de la posición del Partido Comunista de la Argentina, que era de defensa de la dictadura de Videla y de negación de los desaparecidos. Fue la LCR la que desarrolló una solidaridad más activa que cualquier otro partido. El Estado francés tenía una importante política de asilo otorgando el estatuto de refugiado a muchos perseguidos y esa política benefició a unos 941 argentinos entre 1976 y 1983, aunque el gobierno de Francia mantuvo fuertes vínculos comerciales con el gobierno de la Junta Militar. Según Lucas Poy, "Política Obrera, en particular, tenía un importante trabajo en Francia, entre otras cosas por sus vínculos con la Organisation Communiste Iternationaliste [OCI], partido dirigido por Pierre Lambert, que compartió hasta 1978 un agrupamiento internacional con PO y otros grupos trotskistas, como el POR boliviano de Guillermo Lora" ${ }^{\text {. }}$

Marina Franco ha estimado que entre 1960 y 1970 salieron del país unas 128.217 personas y entre 1970 y 1980, entre 236.138 y 339.329. El exilio político argentino de los años "70 representó unas 300.000 personas. Aunque la represión política se descargó sobre una parte importante de la sociedad, "en general quienes pudieron salir del país fueron personas de clase media, con niveles educativos medios y altos, mientras que fue escaso el número de trabajadores y personas de sectores populares que se fueron... es evidente que emigrar fue una posibilidad disponible sólo para algunos y que el fenómeno tuvo una dimensión de clase bastante marcada". En Francia había unos 1.797 argentinos en 1967, 2.171 en 1975 y 3.275 en $1983^{4}$. La autora destaca la presencia escasa de las estructuras partidarias de las organizaciones guerrilleras en el caso de Francia y el hecho de que París era un lugar de paso y alta circulación de los dirigentes de esas fuerzas. En el caso de Montoneros, Adriana Lesgart fue su máxima dirigente en París. La presencia del PRT-ERP fue débil comparada con la presencia de militantes de la organización en Italia, aunque mantuvo un núcleo activo en ese país hasta 1979. Se destaca la actividad de los nucleamientos trotskistas. Política Obrera mantuvo una presencia hasta el final del exilio. También hubo una

\footnotetext{
3 Poy Lucas: "Perfil de Ricardo Falcón". En Revista Archivos de historia del movimiento obrero y la izquierda $\mathrm{N}^{\circ}$ 3. Año II. Septiembre de 2013. p.151

${ }^{4}$ Franco. Marina "Argentinos en Francia durante la dictadura”. Ed. Siglo XXI, Buenos, Aires, 2008. P.39-41
} 
presencia del Partido Socialista de los Trabajadores (PST) y varios militantes trotskistas argentinos se integraron a la LCR. También existió un grupo de exiliados pertenecientes a la organización maoísta Vanguardia Comunista y una presencia de la UCR.

Desde ese espacio de denuncia y defensa de las víctimas de la represión en Argentina, Jorge desplegará una intensa labor militante. En primera instancia en el seno de su propio partido, $y$, en segunda instancia, en la órbita de diversos agrupamientos de solidaridad con las víctimas de la represión y de defensa de los derechos humanos. Al tiempo que por fin ingresaba $^{5}$ al mundo universitario desarrollando sus estudios de grado y posgrado en Historia en la Ecole des Hautes Etudes en Sciences Sociales ${ }^{6}$ - rodeado además de un núcleo significativo de militantes de PO volcados al estudio de esa disciplina entre los cuales se ubicaban, Osvaldo Coggiola, Diana Quattrocchi, Edgardo Bilsky, Zacarías Moutoukias, Bernardo Gallitelli y Ricardo Flacón - efectuó una vigorosa militancia en dos organizaciones de solidaridad: el CAIS (Comité Argentino de Información y Solidaridad) y, ulteriormente, en el TYSAE (Trabajadores y Sindicalistas Argentinos en el Exilio).

Las organizaciones políticas de la izquierda revolucionaria en el exilio cumplieron un rol destacado en la constitución de los organismos de derechos humanos para la denuncia del genocidio y la solidaridad con las víctimas de la represión en la Argentina. Esos grupos nacidos en el exterior organizaron la denuncia internacional de la dictadura militar y fueron un punto de apoyo fundamental para las organizaciones de derechos humanos nacidas en la Argentina entre 1975 y 1977, como Madres de Plaza de Mayo, Abuelas y Familiares ${ }^{7}$.

Desde París J. Gelman será, entonces, el responsable político junto a O. Coggiola y R. Falcón, de una de las varias células desde las cuales Política Obrera ejercitaba sus tareas políticas en la capital de dicho país. Desde allí, denunció a una de las dictaduras más sangrientas de la historia argentina y estableció, junto a otros exiliados, el boicot al Mundial de fútbol de 1978 que se celebraría en Argentina como pantalla a la extraordinaria represión y persecución que se ejercía a la sociedad civil.

Personalmente me queda el sabor amargo de no haber podido coordinar una última entrevista que él mismo sugirió concedérmela porque estaba, como siempre, tapado de trabajo en ese mayo de incipiente frío invernal. Me pareció pertinente recoger para el conocimiento del público en general, este enriquecedor repertorio militante que atravesó Jorge Gelman entre las décadas del '70 y el '80. A través del mismo, es posible pensar que

\footnotetext{
${ }^{5}$ Quien presentó a toda esta camada de jóvenes en la EHESS fue Osvaldo Coggiola, quien ya se encontraba realizando sus estudios en dicha institución. El director de tesis de Jorge Gelman sería el sociólogo Albert Meister.

${ }^{6}$ O. Coggiola afirma que Gelman se había inclinado a hurgar en la historia del agro argentino ya desde la cárcel.

${ }^{7}$ Eidelman. Ariel. Reseña crítica: "Marina Franco, Argentinos en Francia durante la dictadura". Ed. Siglo XXI, Buenos, Aires, 2008, 334 páginas, en Entrepasados. Revista de Historia, año XVII, $n^{\circ} 33$. Buenos Aires, 2008. p. 3
} 
poseyó un compromiso significativo con la cruenta realidad social y política que soportaban los trabajadores argentinos en aquél entonces. Sin embargo, luego de su regreso al país Jorge abandonará el marxismo y la militancia revolucionaria como herramienta política y, también en otro plano, lo descartará lentamente como instrumento analítico y metodológico en sus estudios. Este itinerario similar lo atravesaron varios de los militantes políticos de múltiples organizaciones que, luego de pasar por el exilio y finiquitar sus respectivas carreras universitarias, optaron por dejar a un costado la praxis política y dedicarse enteramente a una profesionalización de tipo intelectual. La mayoría de estos exiliados devino, tras la emergencia de la "primavera alfonsinista", en un acercamiento a las ideas tipo socialdemócratas y en una constante relectura critica de su pasado militante ${ }^{8}$. En fin, nos pareció relevante no olvidar el profundo costado militante de un extraordinario profesor e intelectual como creo que lo fue Jorge Gelman.

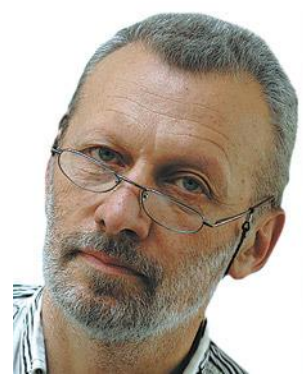

Mi ingreso a Política Obrera es producto de la politización de los tempranos años '70. Debo haber entrado a militar de manera muy espontánea, autónoma, en el colegio secundario de Morón Manuel Dorrego. Y creo recordar que en algún momento apareció gente vinculada a la TERS [Tendencia Estudiantil Revolucionaria Socialista $^{9}$, en la puerta del colegio me contacté con ellos y muy rápidamente a finales de $3^{\circ}$ año (1970-1971), me convertí rápidamente en militante de la $\mathrm{UJS}^{10}$. Y cuando estaba en $4^{\circ}$ año (1972), me puse a organizar el Centro de estudiantes del colegio que no había, fui presidente del centro de estudiantes posteriormente. Y a partir de allí me puse a militar full time para el partido. Este es mi inicio, así me mantuve hasta que caí preso. Es una experiencia que va del '71-'72 hasta el '83. En el exilio yo seguí siendo militante del partido, caí preso el $1^{\circ}$ de mayo de 1975, me mantuve como militante del partido en la cárcel, éramos un grupito del partido que estábamos juntos en la cárcel. Hasta que salí en el '78 y ahí después estuve exiliado hasta mi regreso aquí que me mantuve como militante del partido en París.

Estuve preso del $1^{\circ}$ de mayo de 1975 al 28 de abril de 1978. El partido se acercó vía familiares. Imagínate que, a fines de 1975, es ahí nomás antes del golpe, Isabel Perón había

\footnotetext{
${ }^{8}$ Por ejemplo, Hilda Sábato.

${ }^{9}$ Organización de carácter estudiantil-universitaria de Política Obrera. PO controla que la mayoría de sus miembros estudiantiles ingresen a trabajar en fábricas. A partir de 1967 impulsa la Tendencia Estudiantil Revolucionaria Socialista (TERS), que suministrará los cuadros para la proletarización

${ }^{10}$ Unión de Juventudes por el Socialismo (UJS). Organización de la juventud de Política Obrera creada en 1972.
} 
decretado el estado de sitio y yo me encontraba militando en la huelga de Villa Constitución. Me había proletarizado, cuando terminé la secundaria en el '73, en vez de anotarme en la Universidad comencé a trabajar en una fábrica en Ciudadela con la idea de que era lo que había que hacer como militante del partido. Curiosamente, aunque también premonitoriamente, la fábrica se llamaba estampería "París" (una fábrica textil) y yo terminé luego exiliado en la capital de ese país [risas de entrevistado y entrevistador]. Era una fábrica relativamente chica, había entre 80 y 100 obreros. Con la idea de militar ahí fue un fracaso bastante rotundo mi inserción allí, lo cierto es que al cabo de un año decidí renunciar por qué no cumplía ningún rol, yo seguía en realidad militando fuera de la fábrica con la juventud y en la fábrica la verdad que no logré ningún desarrollo. En términos generales, era una fábrica completamente despolitizada, ninguna actividad sindical ni política, era muy atrasada y yo no pude modificar en nada la situación. Pensá que eran dos turnos de 12 horas con la única idea de juntar el mango (no había ninguna idea de luchar por nada). Y además yo no tenía nada que ver con ese medio y esto es una cosa que tiene que ver un poco con la idea, no sé si errada, de la proletarización de jóvenes de clase media que la verdad que eran un nicho ajeno a ese medio ¿no? Mi experiencia no fue buena, no digo que en general haya sido mala, porque hubo casos famosos de nuestro partido y de otros partidos de izquierda donde la proletarización devino en un liderazgo sindical (ejemplos, los casos de Fisher y Buffano), hubo experiencias "exitosas" de inserción en fábricas grandes politizadas, etc, donde esos proletarizados lograron desarrollar una actividad, pero mi caso fue claramente un fracaso. No sé si por culpa mía, o por el medio en donde me movía. Entonces en esa experiencia estuve un año, desde fines del '74 y principios del '75, justo en ese momento estaba desarrollándose la huelga de Villa Constitución (muy importante), entonces me mandaron a militar ahí, una huelga que estaba concentrada en los barrios, por que las fábricas estaban militarizadas, estaban tomadas por los milicos, entonces los trabajadores de ahí estaban en distintos pueblos que vivían entonces yo militaba ahí con un grupo de compañeros del partido y ahí caí en cana el $1^{\circ}$ de mayo de 1975. Primero me llevaron a Alcaldía, donde está el Museo de la memoria ahora en Rosario, que era una jefatura de policía (que posteriormente me enteré que fue un Centro Clandestino de Detención), allí estuve 10 días una cosa así y de ahí me llevaron a Coronda, la cárcel en Santa Fe. Estuve en Coronda entre mayo, sería finales de mayo o mediados, y en noviembre del '75, nos trasladaron, hubo una especie de motín en la cárcel o de protesta de los presos políticos, y nos repartieron en distintos lugares a varios, o sea algunos quedaron ahí, y un grupo más o menos grande nos repartieron en otras cárceles, y a mí me tocó un grupo que nos llevaron a Resistencia (Chaco) y estuve en Resistencia hasta que salí después. En el marco del Estado de sitio, yo no "tenía juicio", como que nunca estuve preso. Cuando hay estado de sitio el Estado tiene la obligación, en caso de enjuiciarte, de ponerte un abogado y ponerte a disposición del poder ejecutivo nacional (PEN), aunque según la constitución uno tiene el derecho de que si no queres seguir en la cárcel, pedir la opción de salir del país, se llama el derecho de opción justamente. O sea, ellos pueden retenerte en la cárcel indefinidamente mientras sea estado de sitio, pero vos tenes el derecho constitucional de pedir la opción. Antes del golpe yo no estaba de acuerdo y eso 
era una línea del partido (probablemente errónea) con una visión muy exitista de lo que estaba pasando en el país, de que se venía la revolución que estaba a la vuelta de la esquina. Y para mí, lo que estaba a la vuelta de la esquina era el golpe y no la revolución. No estaba de acuerdo, y yo acepté eso, de no pedir la opción antes del golpe, cuando fue el golpe, pedí la opción y tardaron dos años y medio en dármela.

Es que había una política de que la cárcel, cosa que pasaban muchos partidos de izquierda, seguía siendo un espacio de lucha, donde uno seguía militando allí. Ingresabas a la cárcel, con la intención de influenciar, de ganar a otros presos políticos, esa era una política de PO. Era también, como un territorio de lucha política dentro de la propia cárcel, escribíamos periódicos en papel diario, papel de cigarrillo, hacíamos periódicos chiquititos, todo tipo de cosas. Cosa que yo reivindico, no por la utilidad política que tenía, porque no tenía dicha finalidad, pero sí finalmente por que nos permitió no volvernos locos lo que estábamos presos, porque hubo mucha gente que se volvió loca. Estuve preso con Néstor Correa en Coronda y creo que a él también lo llevaron a Resistencia. Rafael Santos fue mi responsable cuando estaba en Morón, de todo Oeste. Había también otro responsable, Daniel Blanco. Él era el responsable fabril. Y en una época fue el responsable, del comité Oeste ahí en Morón. Y Rafa estaba más por encima como responsable, era miembro del CC. Yo le tenía mucho cariño a Rafa, era un tipo muy bueno. Había otro más que estuvo preso, que luego se fue al exilio, se llamaba Bernadro Gallitelli. Y creo que era primo de Ricardo Falcón. Después había otro muchacho, más proletario que también estuvo preso con nosotros, que se llamaba algo así como Carlos Petro. Conmigo también cayó uno que después desapareció, que se llamaba Fernando Sánchez. También cayó con nosotros Diana Quatrocchi. Estábamos militando todos juntos en Villa Constitución y caímos los cuatro juntos. Y Néstor cayó después (20 días después).

En Francia fui responsable de la célula de PO París, que seguíamos militando.... Sobre todo haciendo actividades de solidaridad, denunciando a la dictadura. Marcelo Gramar se mantuvo alejado de las actividades de solidaridad. En ese grupo estaba Ricardo Falcón y quien era su mujer, Diana Quatrochi, y yo fui responsable además de expulsarla del partido como responsable de célula, porque a ella se la vinculaba con la llamada "fracción de María" (esposa de un tal Felix, también dirigentito del PO) en 1978 vinculada a su vez con la OCI (Lambert). Antes de que yo llegara a París hubo una disputa entre la OCI y PO y hubo un grupo del Partido que, un poco aliado a esta fracción, rompieron con el partido.

Estuve haciendo acción de propaganda para que cambie lo que estaba sucediendo en Argentina, también de lo posible ganar gente para el partido. Y bueno, vuelvo a la Argentina con un doctorado bajo el brazo, inmediatamente entro como profesor en la facultad. Regreso en febrero del '84, todavía considerándome militante del partido, y ahí tuvimos un pequeño altercado. Acá en Buenos Aires me incorporan a una célula, ya ni me acuerdo quien era mi responsable, yo estaba en la facultad un tipo grande con un doctorado que se yo, y yo creo que el problema es que me tenían cierta desconfianza, entonces me 
querían disciplinar y me mandaban a repartir volantes a las puertas de las fábricas como si yo tuviera 17 años, una estupidez. Yo no sé si lo hicieron porque pensaban que era un pequeño-burgués y me tenían desconfianza porque había habido un pequeño encontronazo en el tiempo del exilio. Muy rápidamente yo empecé a alejarme y a los tres o cuatro meses dejé de militar y recién elaboré una visión más crítica, mientras estuve adentro me costaba mucho elaborarla. Con esta idea no de que hay que educar y disciplinar a los pequeñoburgueses y mandarlos a la clase obrera y me parece que fue una táctica completamente absurda y yo le decía che mira yo milito en la facultad porque me vas a mandar a una fábrica a las 6 de la mañana a repartir volantes a un lugar donde yo no conozco a nadie y nadie me conoce a mí.

Allá en Francia bueno estuvimos con un grupito en dos organizaciones de solidaridad, sobre todo y en la mayor parte del tiempo en una que se llamaba CAIS (Centro Argentino de Información y Solidaridad), que estábamos con gente de distintas agrupaciones de exiliados de todo tipo, había del ERP, de Vanguardia Comunista y el grupo nuestro era uno que tenía bastante influencia y bueno hicimos cosas bastantes importantes, toda la campaña de boicot al mundial, ahí el CAIS tuvo una participación importante, yo estaba justo llegando, recién empezaba esa campaña. Y después al final se formó otro grupo de solidaridad que se llamaba el TYSAE (Trabajadores y Sindicalistas Argentinos en el Exilio).

A mí lo que me parecía absurdo cuando volví, cosa que no podía ver antes porque además estaba muy metido adentro por la lógica propia del partido, es la incapacidad del partido de observar la realidad, un partido muy atado a dogmas, con una enorme incapacidad de mirar la realidad. Una cosa que me sorprendía, y me acuerdo que lo charlaba con Pablo Rieznik cuando nos reencontramos en la facultad, y yo veía en las asambleas de la facultad que todavía seguían vigentes consignas que nosotros habíamos lanzado en el '75 donde suponíamos que la revolución estaba a la vuelta de la esquina, es decir, huelga general por tiempo indeterminado y asamblea general constituyente, pasaron 8 años de dictadura, de masacre, de derrotas profundas en el movimiento obrero y del movimiento estudiantil y de todo lo que se te ocurra, la izquierda destrozada, vuelvo a la Argentina, y Pablo en una asamblea en la facultad de FFyL dice "porque tenemos que plantear la huelga general por tiempo indeterminado", y yo decía no puede ser que el mundo cambia y que el partido siga diciendo las mismas cosas y yo te digo había una incapacidad de observar la realidad, muy notable. 